\title{
The effects of calcium and glucose supplementation on bone of young female rats in case of disturbances in energy balance caused by their food restriction and exercise
}

\author{
Yuki Aikawa ${ }^{1 *}$, Yuya Kakutani ${ }^{1}$, Ikuko Ezawa ${ }^{2}$, Naomi Omi ${ }^{1}$ \\ From International Society of Sports Nutrition: 8th Annual ISSN Conference and Expo \\ Las Vegas, NV, USA. 24-25 June 2011
}

\section{Background}

Female athletes, with a strong awareness of their weight loss, are prone to restrict their food intake. A major concern arisen from such athletes' daily training would be an imbalance of energy intake and energy expenditure which resulted in an osteoporotic fracture. Calcium (Ca) is a major mineral content in bone, otherwise Glucose (Glu) is an energy source. It is not clear whether $\mathrm{Ca}$ or Glu supplementation have a positive effect on bone in case of disturbances in energy balance caused by their food restriction and exercise.

\section{Methods}

49 female Sprague-Dawley rats (age 8 weeks) were divided into 6 groups: ad libitum feeding $(0.6 \%$ Ca diet) and non-exercise group [Cont group]; ad libitum feeding (0.6\% Ca diet) and exercise group [Ex group]; food restriction $(0.6 \% \mathrm{Ca}$ diet)and exercise group [REx group]; food restriction, Ca supplementation $(1.2 \% \mathrm{Ca}$ diet) and exercise group [REx+Ca group]; food restriction (0.6\% Ca diet), Glu supplementation and exercise group [REx+Glu group]; food restriction, Ca supplementation (1.2\% Ca diet), Glu supplementation, exercise group [REx $+\mathrm{Ca}+\mathrm{Glu}$ group]. They were reared in individual cages during 38 days. Food restriction was $70 \%$ of food intake of the Cont group. Exercise was voluntary wheel running. We measured the number of revolutions every day. After the treatment period, intra-abdominal fat, femur, lumbar spine and tibia were collected.

\footnotetext{
* Correspondence: aikarayuki@gmail.com

'Laboratory of Sports Nutrition, University of Tsukuba Graduate School of

Comprehensive Human Sciences, Tsukuba 305-8574, Japan

Full list of author information is available at the end of the article
}

Statistical analysis was performed using ANOVA followed by a Scheffe's post hoc comparisons test $(\mathrm{p}<0.05)$.

\section{Results}

Final body weight of REx group (167.4 $\pm 10.2 \mathrm{~g}), \mathrm{REx}+\mathrm{Ca}$ group $(172.5 \pm 18.9 \mathrm{~g})$ and $\mathrm{REx}+\mathrm{Ca}+\mathrm{Glu}(229.6 \pm 15.4 \mathrm{~g})$ group compared with the Cont group $(257.5 \pm 12.5 \mathrm{~g})$ were significantly lower $(\mathrm{p}<0.001)$. Running distance was not significant different among the 5 groups (EX group , $\mathrm{REx}$ group, $\mathrm{REx}+\mathrm{Ca}$ group, $\mathrm{REx}+\mathrm{Glu}$ group and $\mathrm{REx}+\mathrm{Ca}$ +Glu group) (7083 $\pm 5575,12021 \pm 7392,10750 \pm 7266$, $10743 \pm 6182$ and $9144 \pm 6048 \mathrm{~m})$. Abdominal fat weight of EX group $(2.05 \pm 0.86 \mathrm{~g} / 100 \mathrm{gBW})$, REx group (1.26 $\pm 0.49 \mathrm{~g} / 100 \mathrm{gBW}), \mathrm{REx}+\mathrm{Ca}$ group $(1.12 \pm 0.63 \mathrm{~g} / 100 \mathrm{gBW})$, $\mathrm{REx}+$ Glu group $(1.72 \pm 0.46 \mathrm{~g} / 100 \mathrm{gBW})$ and $\mathrm{REx}+\mathrm{Ca}+\mathrm{Glu}$ group $(1.56 \pm 1.05 \mathrm{~g} / 100 \mathrm{gBW})$ compared with the Cont group $(4.67 \pm 1.56 \mathrm{~g} / 100 \mathrm{gBW})$ were significantly lower $(\mathrm{p}<0.001)$. Femur weight and femur length of REx group $(0.431 \pm 0.029 \mathrm{~g}$ and $3.151 \pm 0.067 \mathrm{~cm})$ and $\mathrm{REx}+\mathrm{Ca}(0.454$ $\pm 0.045 \mathrm{~g}$ and $3.175 \pm 0.082 \mathrm{~cm})$ group compared with the Cont group $(0.543 \pm 0.030 \mathrm{~g}$ and $3.417 \pm 0.039 \mathrm{~cm})$ were significantly lower $(\mathrm{p}<0.001)$.

\section{Conclusions}

It is concluded that Ca supplementation had no effect, but Glu supplementation had a positive effect on bone under food restriction and wheel running.

\footnotetext{
Author details

'Laboratory of Sports Nutrition, University of Tsukuba Graduate School of Comprehensive Human Sciences, Tsukuba 305-8574, Japan. ${ }^{2} J a p a n$ Women's University, Bunkyo 112-8681, Japan.
}

Published: 7 November 2011 
doi:10.1186/1550-2783-8-S1-P29

Cite this article as: Aikawa et al.: The effects of calcium and glucose

supplementation on bone of young female rats in case of disturbances

in energy balance caused by their food restriction and exercise. Journal

of the International Society of Sports Nutrition 2011 8(Suppl 1):P29.

Submit your next manuscript to BioMed Central and take full advantage of:

- Convenient online submission

- Thorough peer review

- No space constraints or color figure charges

- Immediate publication on acceptance

- Inclusion in PubMed, CAS, Scopus and Google Scholar

- Research which is freely available for redistribution

Submit your manuscript at www.biomedcentral.com/submit

C Biomed Central 